\title{
Numerical simulation of the effect of fault inclination on the sudden water of the fault bottom plate
}

\author{
JIA Xiao-liang \\ Chongqing Research Institute Co, Ltd. China
}

\begin{abstract}
The main reason for the frequent occurrence of water accidents on the bottom plate of the working surface near the mine fault in China is that the excavation activities cause the fault to activate and direct the pressure water of the aquifer. The distribution of ground stress fields and plastic regions under the influence of extraction disturbance spree is analyzed by using the flaC3D simulation software FLAC3D simulation software. The results show that the greater the inclination of the fault, the greater the shear stress and the normal stress at the fault level, and the deeper the activation range of the mining fault is larger than that of the shallow one, and the small inclination positive fault is more likely to produce the fissure between the working surface base plate and the aquifer, and the small inclination positive fault should be left with a wider water-bearing coal column in the actual safety design. Using this software, the evolution of the stress field and plastic zone in the adjacent mining area is a preview, which is of great application value to prevent the surface plate burst water and determine the retention width of the fault waterproof coal column.
\end{abstract}

\section{Introduction}

China's mine bottom plate burst water concentrated in the fault zone near, because of the mining activities caused by fault activation and the channel inge of the aquifer pressure water ${ }^{[1-4]}$, domestic and foreign scholars have carried out a large number of relevant research, and achieved fruitful results. Tan Zhixiang, He Guoqing ${ }^{[5]}$, Through a large number of systematic finite element simulation studies, the general rules of the influence of faults on the development and distribution of water-conducting fracture zones are obtained; Peng Suping, Meng Zhaoping ${ }^{[6]}$ thought that the sudden water accident is very easy to occur in the following circumstances: First, the existence of cutting the bottom plate water-proof ingles of the water-conducting fault, and second, the fault in the natural state of the fault does not guide water. In this paper, the distribution of ground stress fields and plastic zones under the influence of extractive disturbance of different inclination faults is analyzed by using the finite differential numerical simulation software.

\section{2 numericalcalculation model}

The fault inclination is established with 3 numerical calculation models of $25^{\circ}, 45^{\circ}$ and $75^{\circ}$ respectively. As shown in Figure 1 below.

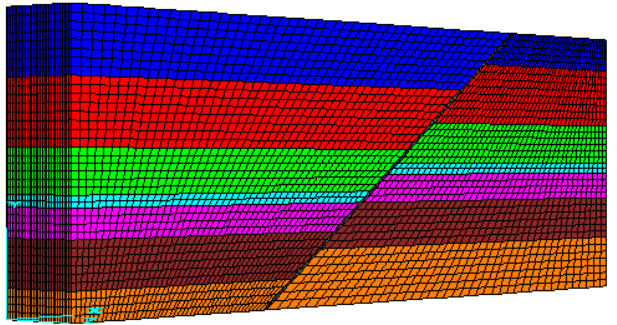

Figure 1 Numerical calculation model

\section{Analysis of numerical calculation results}

\subsection{Stress distribution near faults}

Taking the above-mentioned fault inclination of $45^{\circ}$ fault as an example, the stress distribution near the fault is analyzed after the coal seam is excavated. The design is: the work surface forwards $20 \mathrm{~m}, 35 \mathrm{~m}$, the first main stress distribution cloud map, as shown in Figure 2, 3. 


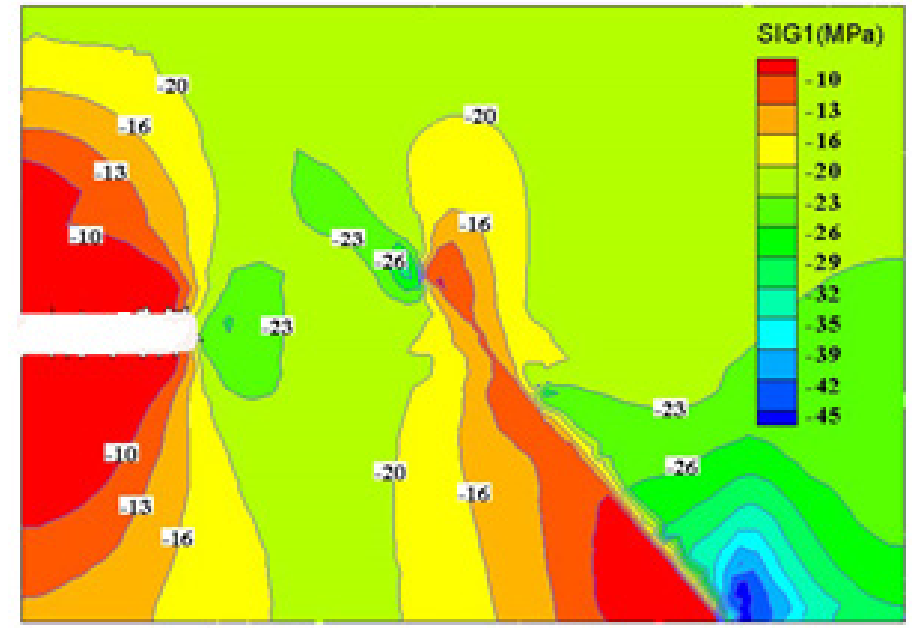

Figure 2 Cloud map of the main stress distribution at $20 \mathrm{~m}$ coal seam mining

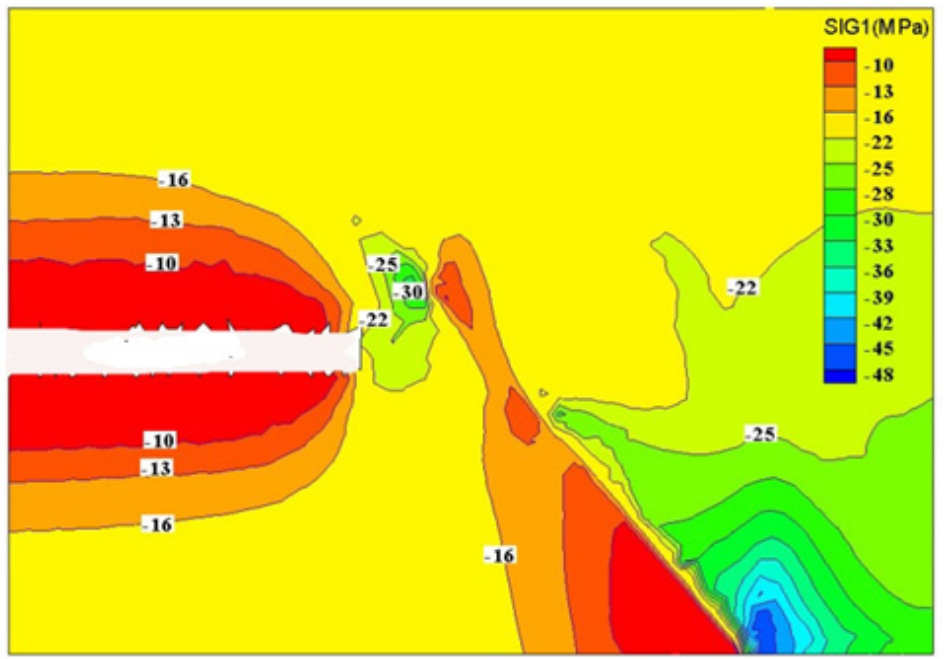

Figure 3 Cloud map of the main stress distribution at $35 \mathrm{~m}$ coal seam mining

When the coal seam mining $20 \mathrm{~m}$, the stress in front of the work appeared high stress concentration, the maximum stress concentration of stress concentration reached $-23.51 \mathrm{Mpa}$, the stress concentration maximum at the tip of the fault reached $-30.31 \mathrm{Mpa}$, the stress concentration area in front of the work and the stress concentration area at the fault tip extinction had not been completed, so no coal and gas protruding occurred at this time; The maximum stress concentration value at the fault tip extinction reaches $-30.80 \mathrm{Mpa}$, due to the influence of work surface mining, the coal rock body in the front fault tip is activated, the stress concentration area above the work side and the stress concentration area at the fault tip is destroyed, and the coal rock into the work surface is highlighted by coal and gas.

\section{Effect of fault inclination on the protrusion of the bottom plate}

Due to the coal seam mining caused by the underground mining area and broken layer activation, in front of the work will produce a water-conducting fissure belt, when the substrate once there is pressure water, pressurized water will be along the fault activation zone and the bottom plate fissure slab into the work surface, lead the bottom plate burst water accident. On the other hand, the pressure water of the aquifer has the effect of weakening and flushing corrosion on fault breaks, which will aggravate the scope of damage and the speed of destruction of the fault layer. In this paper, only when the fault inclination change, under the influence of mining disturbance, the top floor plate destroys the crack and the fault layer activates the resulting crack, so as to show that which inclination fault is more likely to lead to burst water. 


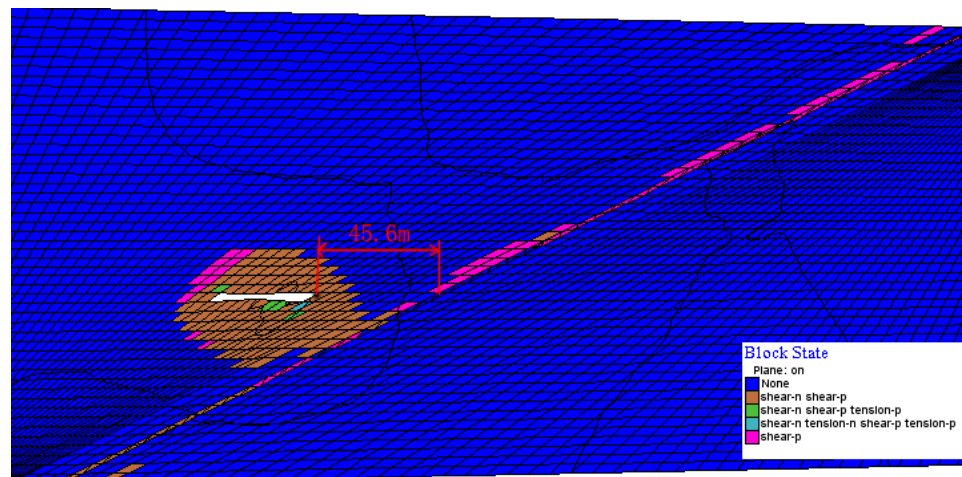

a fault dip $25^{\circ}$

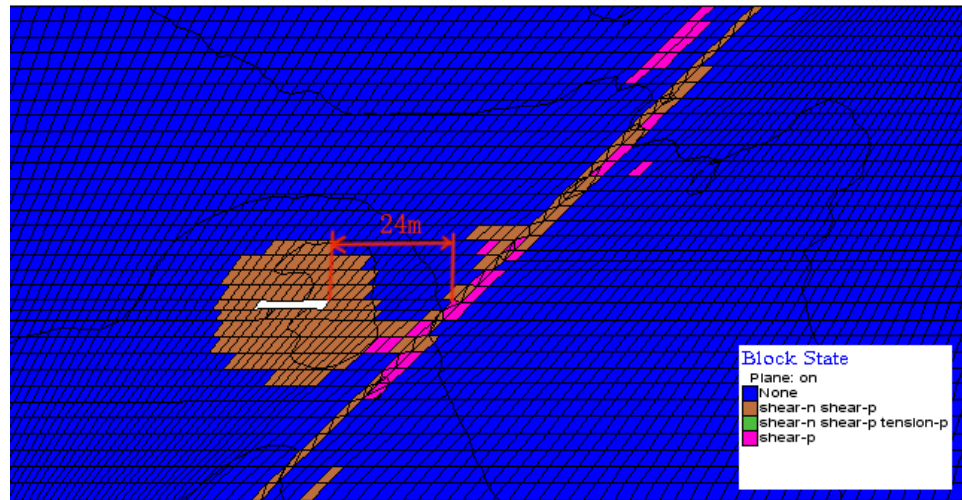

b fault $\operatorname{dip} 45^{\circ}$

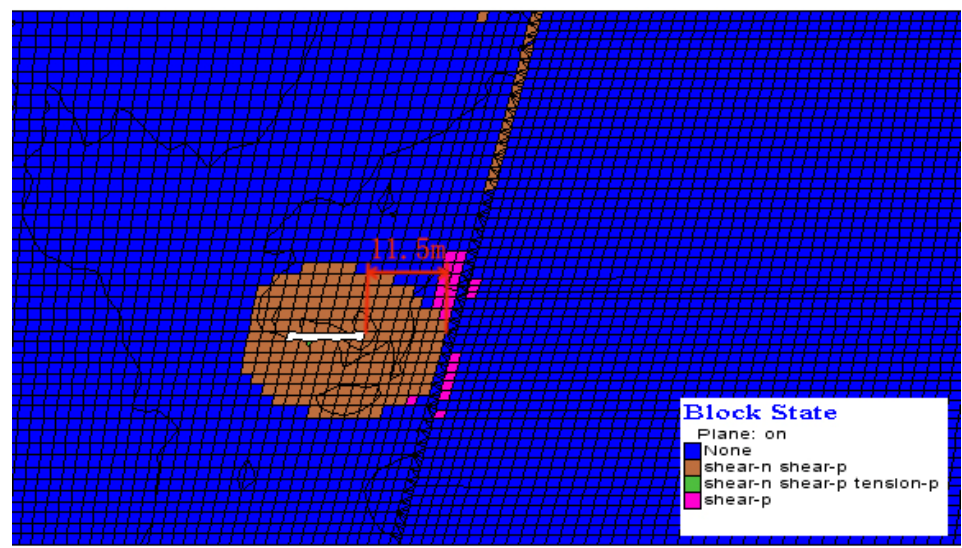

c fault dip $75^{\circ}$

Figure 4 Plastic zone map

Figure 4 is a map of the plastic area of coal rock body near the fault after coal seam mining, from which it can be seen that under other conditions, the small inclination is more likely to produce a fissure through the fault layer, for example, when the fault inclination is 25 degrees, when the coal seam is excavated to $45.6 \mathrm{~m}$ from the fault level, a crack at the fault level is produced.

\section{Example analyse}

The working surface of a mine 1601 in the coking mining area is located on the upper plate of Xiazhuang fault, the original estimate is that the inclination of the fault is 70 degrees, and the waterproof coal column is reserved for $37 \mathrm{~m}, 40 \mathrm{~m}$ thick from the water layer of the base plate. However, from the actual mining process revealed that the fault in the deep inclination becomes smaller, only 55 degrees, so that the actual length of the coal column reduced to $18 \mathrm{~m}$, the water barrier layer is $29 \mathrm{~m}$ (Figure 5), and finally under the pressure of $1.78 \mathrm{Mpa}$, the sudden water volume reached $92.78 \mathrm{~m} 3 / \mathrm{min}$, resulting in flooding wells.

Based on the numerical calculation conclusion, the analysis indicates that the above-mentioned causes of the sudden water are: (1) the inclination of the square fault before the work is too large, resulting in the actual retention waterproof coal column width is too small; (2)the small inclination positive fault, to consider the characteristics of mining easier activation work surface plate, leaving a sufficiently wide fault water-free coal column. 


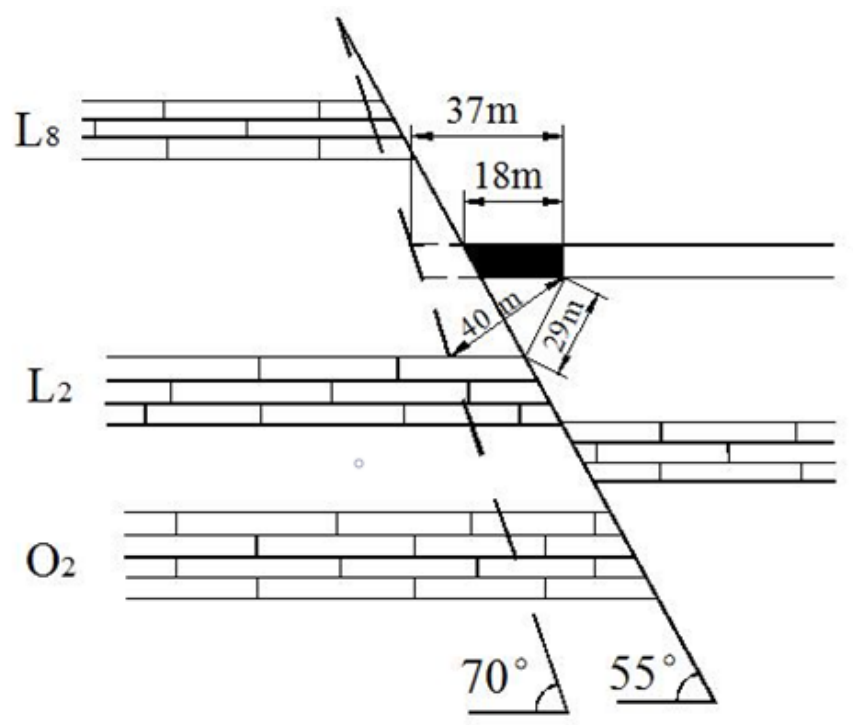

Figure 5 Work surface water profile diagram

\section{6 conclusion}

The following conclusions can be drawn from the analysis of the simulation results:

(1) Under the influence of extractive disturbance, the small inclination positive fault is more likely to produce cracks through the base plate and aquifer, which induces the bottom plate burst water accident.

(2) It is feasible to preview the evolution of the ground stress field and plastic zone of the fault zone in the adjacent extraction area by numerical simulation, and to make the prediction of the surface plate burst water and the retention width of the fault waterproof coal column.

\section{references}

1. Li Liangjie, Qian Minggao, Yin Youquan. Coalfield Geology and Exploration1997, 25(1): 36.

2. Zhu Xingshan, Xu Fengyin. Back-picking work surface fault near the rock protruding numerical simulation study . Journal of Shandong Mining College, 1995, 14 (3) :26-27.
3. Wang Jin'an, Liu Hang, Li Tie. Numerical Simulation Of The Power Hazard Zone of Near-Fault Mining . 2007, 26 (1) : 28-35.

4. Zhang Jincai, Zhang Yuzhu, Liu Tianquan. Rock seepage and coal seam plate burst water $[\mathrm{M}]$. 1997.08

5. Tan Zhixiang, He Guoqing.The development law of the water-conducting fissure zone under the influence of fault [J]. 1997,25(1): 36

6. Peng Suping, Meng Zhaoping.The theory and practice of the geological geology of mine engineering .2002. 103

7. Zhang Jincai, Zhang Yuzhu, Liu Tianquan. Rock seepage and coal seam plate burst water 1997.08

8. Wu Qiang, Pan State, Guan Enda.A summary of the study of sudden water disaster seisking disaster sourating in the coking mining area $1995,6(4)$ : 44-49.

9. The characteristics of the fault burst water in the coal mine of Xing mazhuang and its prediction and prediction method 2005, (7) : 43-45. 